\title{
Review of blockchain-based distributed energy: Implications for institutional development
}

\author{
Amanda Ahl ${ }^{1, *}$, Masaru Yarime ${ }^{2,3,4}$, Kenji Tanaka $^{5}$, Daishi Sagawa ${ }^{5}$ \\ 1 = Department of Innovation Science, School of Environment and Society, Tokyo Institute of Technology, 3-3-6 \\ Shibaura, Minato, Tokyo 105-0023, Japan. \\ 2 = Division of Public Policy, The Hong Kong University of Science and Technology, Clear Water Bay, Kowloon, \\ Hong Kong. \\ 3 = Department of Science, Technology, Engineering and Public Policy, University College London, Gower St, \\ Bloomsbury, London WC1E 6BT, United Kingdom. \\ 4 = Graduate School of Public Policy, The University of Tokyo, 7-3-1 Hongo, Bunkyō, Tokyo 113-8654, Japan. \\ 5 = Graduate School of Engineering, The University of Tokyo, 7-3-1 Hongo, Bunkyō, Tokyo 113-8654, Japan. \\ * Corresponding author: ahl.a.aa@m.titech.ac.jp; +8170-4213-2970.
}

\begin{abstract}
The future of energy is complex, with fluctuating renewable resources in increasingly distributed systems. It is suggested that blockchain technology is a timely innovation with potential to facilitate this future. Peerto-peer (P2P) microgrids can support renewable energy as well as economically empower consumers and prosumers. However, the rapid development of blockchain and prospects for P2P energy networks is coupled with several grey areas in the institutional landscape. The purpose of this paper is to holistically explore potential challenges of blockchain-based $\mathrm{P} 2 \mathrm{P}$ microgrids, and propose practical implications for institutional development as well as academia. An analytical framework for P2P microgrids is developed based on literature review as well as expert interviews. The framework incorporates 1) Technological, 2) Economic, 3) Social, 4) Environmental and 5) Institutional dimensions. Directions for future work in practical and academic contexts are identified. It is suggested that bridging the gap from technological to institutional readiness would require the incorporation of all dimensions as well as their inter-relatedness. Gradual institutional change leveraging community-building and regulatory sandbox approaches are proposed as potential pathways in incorporating this multi-dimensionality, reducing cross-sectoral silos, and facilitating interoperability between current and future systems. By offering insight through holistic conceptualization, this paper aims to contribute to expanding research in building the pillars of a more substantiated institutional arch for blockchain in the energy sector.
\end{abstract}

\section{Highlights:}

- Blockchain has significant potential in energy sector development

- Holistic review of factors of blockchain-based P2P microgrids

- Multi-dimensional analytical framework proposed

Key words: Blockchain; Microgrid; Peer-to-peer; Renewable energy; Institutions

Abbreviations: Alternative current (AC); Back-to-back (B2B); Central processing unit (CPU); Combined heat and power (CHP); Direct current (DC); Demand response (DR); European Union (EU); Feed-in-tariff (FIT); Greenhouse gas emission (GHG); Information and communication technologies (ICT); Internet of things (IoT); Operations and maintenance (O\&M); Peer-to-peer (P2P); Proof of Identity (PoI), Proof of Stake (PoS); Proof of Work (PoW); United Nations Framework Convention on Climate Change (UNFCCC); Virtual power plant (VPP). 


\section{Introduction}

The global economy is increasingly competitive, with growing demands that cannot be sustainably met by conventional energy systems [1]. The world's energy consumption grew by $2.1 \%$ in 2017 , with fossil fuels supplying $81 \%$ of total demands [2]. In light of climate change, there are pressures to reduce emissions through energy efficiency and renewable energy. The share of renewables is indeed rising rapidly, having supplied $25 \%$ of the world's energy in 2017 [2]. Several nations have high targets, such as a renewable energy share of 32\% by 2030 in the European Union (EU) [3] and 100\% by 2040 in Sweden [4]. However, with the distributed and intermittent nature of renewable sources, new technologies are necessary to take this expansion to the next level.

The use of local renewable energy can contribute to environmental sustainability and socioeconomic growth [5]. Distributed energy systems, including local renewable sources and energy storage, will continue to develop by leveraging technological advances $[6,7]$. The future of these systems is complex, involving an interplay of prosumers (both producers and consumers) and smart devices that communicate in real time [7-11]. It is clear that this future cannot be efficiently managed with the centralized markets of today [8, 11, 12], with growing focus on information and communication technologies (ICT) to mediate more sustainable, distributed energy $[5,13]$.

Blockchain is rapidly gaining momentum in this context as an ICT platform. Also referred to as the "Internet of Value" [14], it is a distributed ledger leveraging consensus procedures and cryptographic security [15]. While the technology is not new, the emerging applications of blockchain are highly disruptive [16, 17] due to its irreversibility, near-incorruptibility, and aptitude to decentralize markets [17]. There are several benefits of this decentralization, including fault tolerance, attack resistance and avoiding collusion and price cartels [18]. The energy sector is no exception. Blockchain has also been discussed as the "Internet of Energy" [19, 20], enabling transparent, distributed prosumer markets [21]. This can contribute to a shared energy economy $[19,22]$ with a platform upon which all people can produce, sell, and purchase energy [21].

Nevertheless, blockchain energy applications are still emerging with several grey areas, including its institutional [14, 16, 23] and socioeconomic [5] consequences. There is lacking insight on prospective prosumer markets for distributed energy, which would be valuable in the formation of more apt institutions. There is also a lack of research on the holistic conceptualization of blockchain-based microgrids [24] that combines numerous perspectives in analysis. The purpose of this paper is to holistically explore potential challenges of peer-to-peer $(\mathrm{P} 2 \mathrm{P})$ blockchain-based microgrids, and propose practical implications for institutional development as well as academia. First, a brief background on the mechanisms of blockchain and its potential in energy sector progress is given. Secondly, a comprehensive critical review of blockchain, its application in $\mathrm{P} 2 \mathrm{P}$ microgrids, and related opportunities and challenges is carried out based on literature and expert interviews. Thirdly, an analytical framework for P2P microgrids is presented comprising of the key findings of this review. Finally, the framework is discussed, concluding with implications for its utilization in facilitating institutional development and further research.

\section{Overview of blockchain and prospects in the energy sector}

Blockchain is rapidly emerging as a potential game changer of how value is created in all sectors and even how society functions at large. It is essentially a distributed ledger meant to record information openly and 
in a decentralized manner [7, 25], applicable to both tangible and intangible assets [15]. Each transaction is stored as a block upon consensus of all parties, and thereafter linked to previous blocks forming a chain which is shared within the network for transparency and accountability [13, 26]. The technology received over 1.4 billion USD in commercial investment 2014-2017, with agencies also increasingly running trials for public services [15]. For example, the first blockchain-based bond was released in Australian dollars in 2018, created by the World Bank Innovation Lab and the Commonwealth Bank of Australia [27]. In addition, numerous central banks such as in Sweden, Denmark, and the United Kingdom are exploring possibilities of creating national digital currencies [28].

\subsection{A future with smarter grids and local energy markets}

Several authors discuss that future energy systems will be distributed, supported by smart sensors and ICT for bi-directional communication among all entities on smart grids [1, 6, 29]. These smart grids can act in real-time, scheduling loads based on system demands, generation, prices, and contracts [6]. Smart grids as well as microgrids are expected to continue to become a new energy paradigm [6, 30], with microgrids allowing for higher shares of local renewable energy, prosumers trading within communities, and increased resilience $[5,30]$.

Microgrids are a collection of local, distributed generation and loads in a coherent system connected to the utility grid [31,32], with the ability to operate on-grid as well as off-grid in islanding mode [24]. These systems are not yet used in several regions, but projections indicate a potential annual market value of 200 billion USD [24]. Microgrids enable local energy markets, which are geographically limited with unique pricing mechanisms between interconnected actors [5]. Renewable sources can be balanced via storage and ICT [19], with excess energy automatically stored or sold based on pre-determined business models [33]. If blockchain technology is introduced, P2P trading may also be conducted within microgrids, in addition to electricity exchange via physical and virtual utility grid connection [21, 34].

\subsection{Blockchain in future energy development}

Decentralized energy systems have been extensively discussed in academia [11, 30, 35]. It is important to also discuss a further transition to distributed systems which blockchain technology may facilitate. A simplified example of this shift and associated changes in electricity and information flows are shown in Figure 1. Centralized systems were originally designed for the flow of electricity from high voltage fossil fuel-based generation to low voltage downstream loads [35]. Smart grids and microgrids have increasingly contributed to decentralized energy systems, with growing residential, small- and medium-scale renewable energy generation. In prospective distributed systems, power producers, prosumers, and consumers may directly buy and sell power with one another in P2P networks, for which blockchain is a key emerging and enabling technology $[5,7,8,11,34]$. Some authors also propose that power may be shared between microgrids in multi-microgrid networks [11].

With blockchain platforms, transactions may eventually be reduced to real-time [25] and even at dispersed, micro-scales [5]. In a distributed system, all participants in the network can have transparent access to information, with automated value exchange facilitated without a third party [22]. In terms of security, due to its distributed structure, blockchain cannot be hacked easily as on a central server [22]. Each block is coded with a hash function which affects ensuing blocks, making any interference conspicuous [36]. Such characteristics in P2P models can contribute to making distributed energy a reality [19, 22, 25, 37]. 


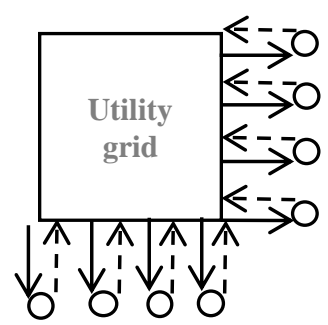

A) Centralized

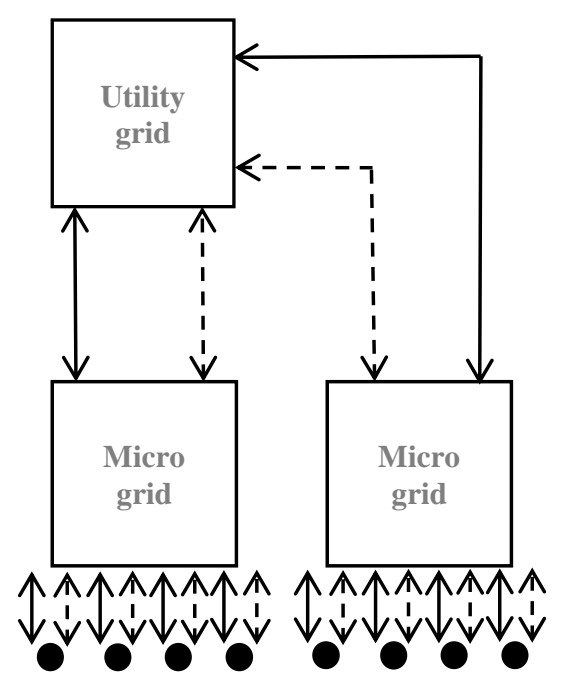

B) Decentralized

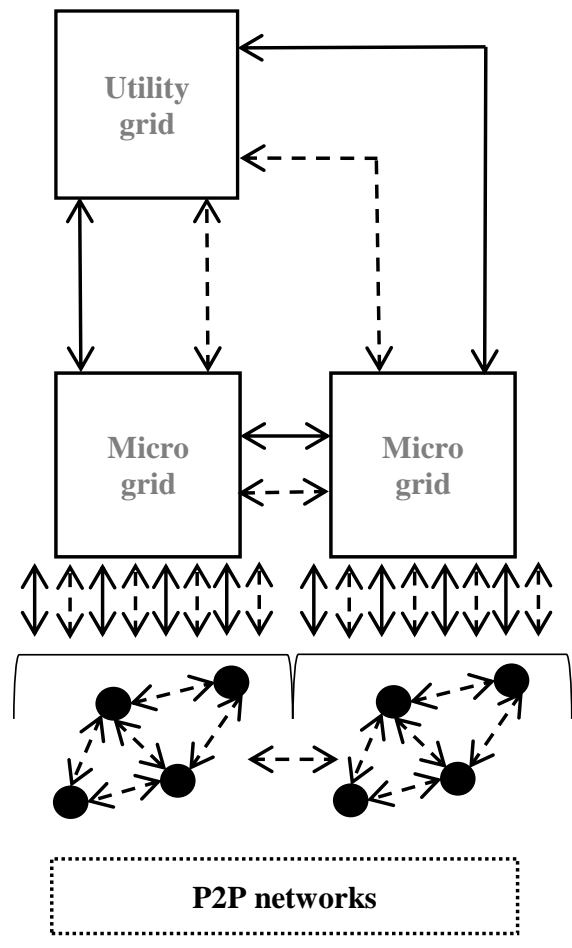

C) Distributed

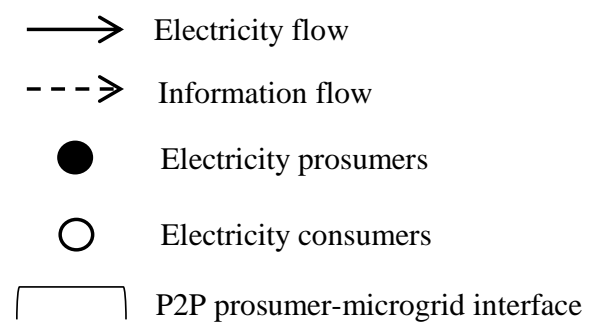

Fig. 1 Simplified overview of potential transition from A) Centralized, to B) Decentralized, to C) Distributed energy systems with microgrids and P2P networks.

Blockchain can be adopted for the matching of energy demands considering prosumer supplies and with conditions established in smart contracts [8] via which excess energy can be sold at transparent prices [38]. A smart contract is encoded in the blockchain, and automatically carries out transactions depending on predetermined conditions $[9,10,26]$, such as preferred energy sources and price ceilings and floors $[5,9,34]$. In this way, control and power is shifting to citizens in more decentralized forms of governance [22]. With the participation and data ownership possible on blockchain platforms, users will be more part of the system than at its edge [22]. This kind of "democratization of electricity" via "citizen utility", as described by Green and Newman [13], may drive a holistic transformation for more sustainable energy development.

\section{Methodology}

Blockchain application in the energy sector is a new, relatively uncharted research topic [14, 23, 24]. An exploratory methodology is needed when a research problem has few earlier studies, for building new insights and familiarity through initial investigations [39]. This approach is especially useful to investigate boundaries in which issues and opportunities may reside, and identify factors relevant for further research 


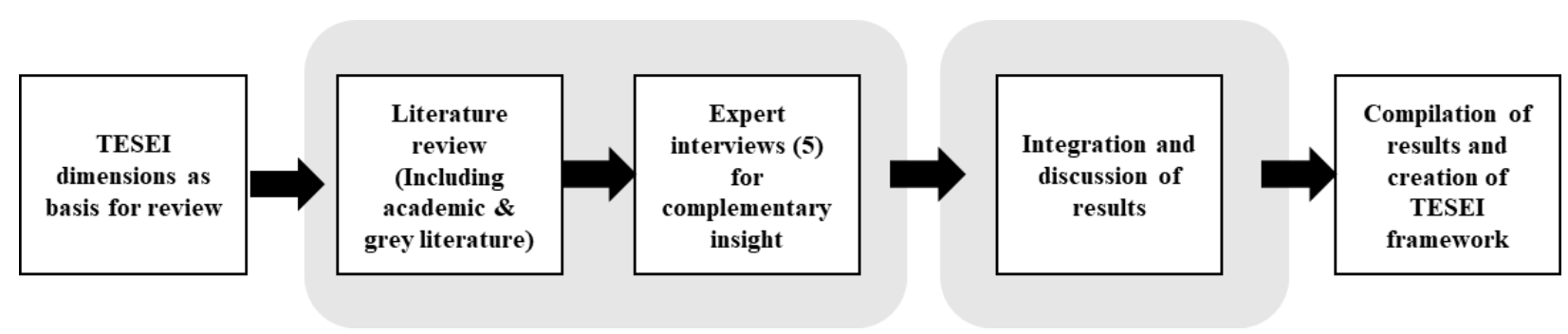

Fig. 2 Simplified schematic overview of the methodological approach of this study (TESEI: Technological, Economic, Social, Environmental, Institutional)

[40]. Hence, an exploratory approach was considered appropriate for the purpose of this paper, in conceptualizing blockchain-based P2P power systems in a holistic framework. A schematic overview of this approach can be seen in Figure 2. This builds on Mengelkamp et al. [34], which developed and adopted a series of microgrid components for a case analysis.

An analytical framework was created, including five dimensions and multiple sub-factors. Titled TESEI, the framework includes 1) Technological, 2) Economic, 3) Social, 4) Environmental and 5) Institutional dimensions. The dimensions and factors incorporated in TESEI were based on an extensive literature review on blockchain-based P2P networks and microgrids. This review included academic literature as well as news articles, conference presentations, press releases, and reports, aiming to capture the rapid change and novel nature of blockchain and its potential applications in energy. In addition, five experts were interviewed, in order to incorporate complementary insights. An expert was identified as an individual with experience and/or actively working in either industry or academia related to blockchain and blockchainbased energy systems. The experts and affiliations can be seen in the References of this paper, referred to as 'Personal communication'. Three interviews were carried out face-to-face, and two via conference call. The experts were asked to discuss challenges of blockchain-based P2P microgrids for each dimension in TESEI. These experts were not presented with any pre-determined literature-based findings of TESEI factors prior to the interview. Interviews were semi-structured and open-ended, with identical phrasing of questions for each interviewee followed by various clarification questions. This structure enables interviewees to give comprehensive and in-depth responses [41], which is useful for an exploratory study.

The conditions and opportunities of blockchain-based P2P electricity would indeed be dependent on jurisdiction, and in turn the developed framework may not be universally generalizable. However, TESEI may be built upon and expanded in academia. While microgrids are valuable for remote communities without access to electricity [11], the focus of TESEI is on areas in which microgrids can interconnect with utility grids. Furthermore, combined heat and power (CHP) can indeed improve flexibility and energy conversion efficiency [12], but TESEI is limited to electricity. The potential of blockchain platforms in the context of off-grid solutions as well as CHP-based microgrids may be two interesting areas for further research, but are not within the scope of this study.

\section{Analytical framework development}

Several studies have explored and established frameworks for energy system decision-making, at large focusing on social, environmental, economic and technological criteria [42-44], but often omitting an explicit inclusion of institutions. A few incorporate this, such as the multi-tier framework for renewable energy evaluation by Katre and Tozzi [45], with an institutional dimension centering on governance and 
community involvement. Wu and Tran [20] discussed the application of blockchain in sustainable energy systems, and identified blockchain regulation in their outline of key challenges in addition to technical bottlenecks such as data storage, cybersecurity, and skill shortages [20].

TESEI aims to further integrate the multi-dimensionality of blockchain-based P2P microgrids in a comprehensive, holistic framework. TESEI was developed with multiple dimensions because issues of blockchain-based P2P microgrids would be multifaceted, comparable to the energy system decision-making frameworks discussed earlier [42-45]. This holistic overview is valuable in answering how technological innovation can be expanded to institutional readiness by also understanding economic, social and environmental dimensions. It is suggested that the framework may offer further useful insights and aid in blockchain-based microgrid analyses. Each dimension as well as their inter-relatedness is useful in such analyses, and important in institutional development. As put by Afgan et al. [44], there is value in the nonnumerical information found in relations among criteria in energy system assessments. TESEI is proposed for application among practitioners as well as researchers when analyzing blockchain-based microgrid cases. The framework itself may also be built upon in academia. Hereafter, each dimension is explored followed by a discussion of the established analytical framework, dimensions, and factors therein.

\subsection{Technological dimension}

Technological decisions are needed at the onset of any new energy project [43]. Mengelkamp et al. [34] found that the technological dimension of blockchain-based microgrids is relatively established as opposed to others, such as social and regulatory factors. The technological aspect of blockchain for distributed energy has gained momentum in academia. For instance, Oh et al. [46] modelled a multi-chain blockchain platform based on power-trading scenario data, finding that power and financial transactions can be conducted effectively and simultaneously. Tanaka et al. [9] conducted simulations for P2P power-trading on a private Ethereum blockchain, with various solar PV generation, storage, and load conditions. Local exchange with bi-directional digital inverters was found to reduce energy waste, even without storage [9]. Pop et al. [8] explored blockchain for demand response (DR) in Ethereum-based simulations with smart contracts, finding that energy demands and supplies could be balanced. Hwang et al. [21] investigated prosumer business models in a laboratory testbed, and proposed a transaction model for efficient and virtual trading via blockchain and the Internet of Things (IoT).

\subsubsection{Blockchain: Technical issues and prospects}

Before moving forward, it is important to discuss potential technical challenges of blockchain and impacts on P2P microgrids. Several authors highlighted the computational costliness of the consensus mechanisms of blockchain and accompanying difficulties in scalability [10, 17, 20, 34, 47]. For each new block, a high energy intensity may be needed, especially when uploaded information increases [17, 34]. Proof of Work (PoW) is a consensus mechanism requiring a complex mathematical problem to be solved before a new block is added in order to, for example, avoid double-spending [10]. This requires high central processing unit (CPU) power, depending on computational difficulty, which in turn lies behind the high energy intensity of PoW [37, 48]. In addition, platforms such as Bitcoin and Ethereum as of yet have low transactions per second (tps) [49], ranging from 3-7 and 12-30 tps respectively, inhibiting scalability [50].

Such issues contradict the environmental and economic sustainability which distributed energy systems aim to promote. High energy intensity and low tps levels in blockchains may inhibit scalability of P2P electricity 
networks. Nonetheless, new resolves are continuously being introduced to improve scalability, performance, and security, and decrease latency [18]. For example, Block.one is a company developing a blockchain platform, EOS, with plans to scale to 10,000 tps and above [51]. This has been possible via new blockchain mechanisms, including sharding, whereby a series of side-chains are created and run in parallel. This aids scalability due to decreased information loads on a single chain [52]. While this could enable scaling as well as cross-sectorial business models [53], inter-shard communication remains a key area in need of further development [52].

Also in progress are various new consensus mechanisms which may contribute to reduced energy intensity. This may in turn contribute to the scalability and sustainability of blockchain-based microgrids. Proof-ofStake (PoS), as opposed to PoW, verifies a new block transaction based on assets or owned cryptocurrency units (stake), thereby not requiring particular hardware and high energy consumption [37, 54, 55]. Another example is Proof of Identity (PoI), which adopts hash-based user identification, requiring lower CPU, energy consumption, and transaction costs than PoW [34, 37]. PoI may be suitable for private [5] or semiprivate [37] networks with selective access in local energy markets. In a semi-private blockchain, a single entity grants access to any qualifying user, while a private blockchain has fewer members and is tightly managed by those members [56]. It is clear that several blockchain platforms and consensus mechanisms are developing, and the varieties that may be useful in the energy sector are in need of further exploration.

\subsubsection{Energy management system}

Hardware and software are vital for microgrid quality, profitability, and market support [57, 58], by managing bi-directional real-time flows of energy and information with smart metering to balance supplies and loads [24, 57]. This would be an imperative basis for market efficiency, new market player introduction, optimal management of congestion, and renewable energy integration [12]. Technical energy management and market support can facilitate higher self-sufficiency in P2P energy models [59]. With the complexity of multiple prosumers in a P2P network, an energy management system for the dispatch and trading of electricity and storage is a needed $[34,59]$. In this, automatic management based on bidding strategies, supplies and loads can balance energy in the microgrid [29, 34, 59], and manage peak power to avoid technical burdens and costly network reinforcements [59]. In this discussion an important consideration is also the extent that smart grids and networks have already expanded, which affects the potential for reactive power via digital inverters [12].

Several authors $[9,11,12]$ highlight the importance of an energy management system that keeps frequency and voltage levels within acceptable ranges, thereby also enabling utility grid connection. As demonstrated by Tanaka et al. [9], a back-to-back (B2B) structure can manage the challenge of grid interconnection through bi-directional power voltage and frequency conversion. Low voltage alternative current (AC) on the distributed system side can be converted to direct current (DC) and again to high voltage AC on the main utility grid (and vice versa). The B2B structure, as shown in Figure 3, can reduce constraints related to differences between the utility grid and microgrids, as the microgrid frequency and voltage is isolated [9]. Thereby, the distributed side does not disrupt the utility grid, and technically facilitates interconnection. In this context, microgrid islanding and reliability are facilitated with branched system energy-balancing on multiple levels [33]. Cruz et al. [12] similarly discussed the potential of meshed networks to shift between closed and open branches in dynamic distributed energy systems. Previous studies have shown that such networks enable distributed resource integration, while maintaining reliability [12]. 


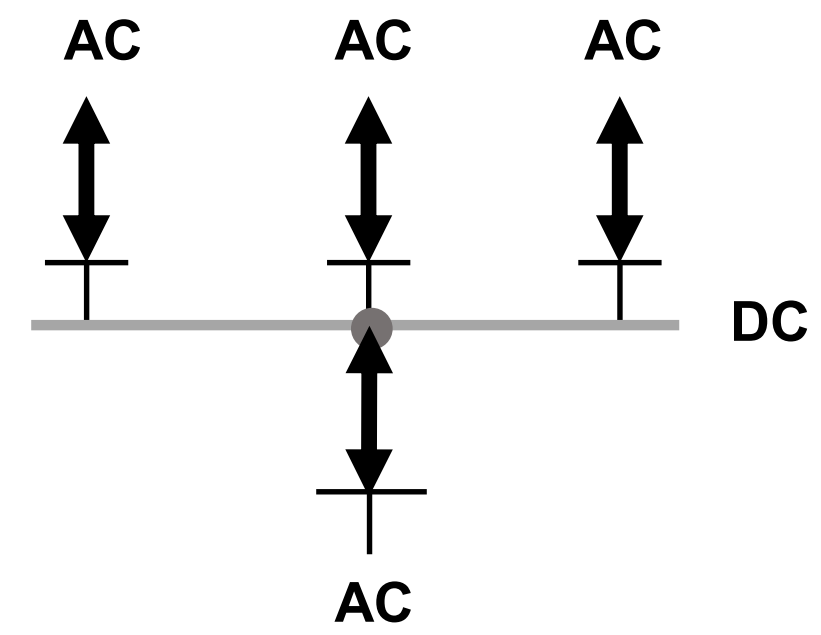

Fig. 3 Back-to-back (B2B) power conversion.

Adapted from Tanaka et al. [9]

\subsubsection{Power grid}

The interconnection of microgrids with the utility grid is also an important consideration to improve system reliability [24, 34]. In addition, microgrid islanding is a key element to incorporate in planning [5, 11, 12, $31,57]$, for example as it offers further local power supply reliability $[12,60]$ and may be required by certain policies [61]. Energy storage can further contribute to reliability, fault prevention, enable ancillary services, and alleviate over- and under-voltages [11]. In this way, energy storage can be discussed as a key enabling technology for stability and power quality [12] which should be reflected in P2P microgrid advances.

In sustaining the technical system and reliability, processes for operations and maintenance (O\&M) of the microgrid and equipment are important in long-term planning [60, 62]. As highlighted by Zhou et al. [59], an increasing amount of P2P energy-sharing mechanisms is being released. In both short- and long-term planning, an important challenge to explore further is also the interoperability with physical utility infrastructure required in any transition to blockchain-based P2P microgrids [63]. Killmeyer et al. [15] similarly highlight the significance of effective system integration and platform scalability. With an increasing frequency of power exchange in such P2P networks, microgrid power loss tracking and attribution would also be important for accurate evaluation and pricing of energy transactions [64].

\subsubsection{P2P network}

In P2P energy networks, every node needs to be responsive to grid conditions, prices, and local supplies and demands [19]. Blockchain is a promising method for this market support due to simplified metering and billing [33]. Bidding strategies can be matched with smart contracts, and payments carried out in digital currency based on smart meter values. The information system is a channel for microgrid responsiveness in market access and monitoring, by connecting all prosumers and consumers [34] in an essential software layer for P2P power trading networks [33].

Smart contracts need to notify the system on updated bidding strategies [24, 34], coupled with effective verification mechanisms, such as PoI [34]. In addition, when building the P2P blockchain network, important components include consensus algorithms, cryptography, data storage, and decentralized 
applications such as virtual wallets for individual balance checks [24]. Each of these components and associated challenges, such as platform scalability, present important arenas for further research. For example, $\mathrm{Wu}$ and Tran [20] highlight the process of storing all transaction records, which would require large capacities of data storage performed synchronously across all blockchain nodes, and thereby higher energy consumption. In addition, Mishra [48] emphasized the need to explore trade-offs related to cybersecurity levels of various consensus mechanisms based on requirements in the energy sector. Such requirements are related to the technical system as well as economic, social, and environmental sustainability. In advancing P2P microgrids, the remaining dimensions of TESEI are useful in discussing institutions conjunctively with technological change.

\subsection{Economic dimension}

\subsubsection{Energy market mechanisms}

Several authors emphasize technological innovation alongside market liberalization as an enabler of energy sharing, trading, and balancing in microgrids $[31,57,58]$. The effective development of microgrids would enable diverse and networked generation and loads [11], laying a ground for new dynamic markets. An introduction of $\mathrm{P} 2 \mathrm{P}$ power would require new market rules and mechanisms, such as internal microgrid pricing [59]. For effective market competition, clear and flexible pricing and tariff structures are needed, based on fixed charges for infrastructure and volumetric charges via time-of-use or real-time pricing [57]. The fixed costs would depend on ownership models and regulations [31, 62].

Potential structures and mechanisms for P2P microgrid participation in various types of markets are of interest to explore further. Worldwide, several energy markets are liberalized or in the process of liberalization, leading to numerous new opportunities, such as energy balancing, ancillary, and retail markets. One potential pathway is that P2P microgrids, which can aggregate prosumer supplies [21, 34], provide ancillary services, such as balancing support [32]. Market competition would benefit from the setup of an ancillary service market: an important consideration for $\mathrm{P} 2 \mathrm{P}$ microgrids as it could increase profit for voltage, frequency, restoration, peak load, and balancing support [32]. However, at present there are no clear scenarios for prosumer participation in most markets. The interplay of P2P microgrids and energy market developments is an interesting area for further study in both academia and policy.

\subsubsection{Smart contracts and market interoperability}

$\mathrm{P} 2 \mathrm{P}$ energy-sharing requires both new technologies and business models, which may vary greatly based on participating entities, value propositions, and profit structures [19, 59]. With blockchain, diverse loadscheduling based on frequent fluctuations in both internal and wholesale market prices is made possible [24]. Considering the decreased power settlement time [16, 24, 37], ability to conduct micro-payments [5, 16], and complexity of the P2P network, real-time pricing settlement is suggested for blockchain-based microgrids [24, 34]. Market transactions based on real-time demands and supplies (including storage) are possible via smart contracts, in which automated business models for sales and purchases can be encrypted [24].

Automated buying, selling, and scheduling of transactions is possible via smart contracts integrating prosumer and consumer preferences. Energy markets with shorter temporal resolutions facilitate pricing that matches real system conditions [12], for more efficient billing and transaction clearance processes. 
Abilities to set up such smart contracts among multiple consumers, prosumers, and producers would also influence market competition and efficiency in P2P networks [63]. Such networks may involve both conventional utility contracts and smart contracts. However, the interplay of these two systems as well as how P2P dynamics would fit into the overall energy market balance is uncertain [63].

The enhanced transaction efficiency and reduced latency of blockchain [15, 22] present significant opportunities for economic efficiency. In order to take advantage of this, however, the interoperability of conventional and smart contacts would also require advancement [63]. The ability of blockchain to effectively and transparently track distributed data $[13,26,17]$ may be useful for following power sources, contracts, and financial information in energy systems in this context. In addition, this may be valuable due to abilities to standardize data formats across organizations [65]. Nonetheless, the interplay of smart contracts and conventional systems in transitioning from current to potential future energy markets is of interest to be explored further. In this picture, the creation of more defined market roles of prosumers and microgrids is suggested as an important component for interoperability as well as for prosumer business models.

\subsubsection{Prosumer business models}

Prosumers may strategize self-consumption, storage, and power purchases based on wholesale and local P2P market prices. These choices may also depend on several other factors, such as preferred levels of renewable energy [34] and even options of selling ancillary services, all for which strategies can be encrypted in smart contracts [24]. In exploring prosumer business models, Zhou et al. [59] highlighted the importance of value-tapping and participation willingness, which involve quantifying economic benefit for the community and individual, respectively. Value-tapping is the community cost-saving potential gained by participating in the $\mathrm{P} 2 \mathrm{P}$ network, as well as the degree of additional attainable benefit [59]. Participation willingness is related to this cost-saving potential for an individual [59].

Economic benefits can be further explored based on selectivity and locality [32]. Locality refers to the ability of microgrid participants to purchase electricity at wholesale prices, which are lower than retail prices due to avoided network, service, market, and tax fees [32]. Selectivity in turn refers to the ability of prosumers to exploit fluctuating wholesale prices, selling power when prices are high and buying when they are low [32]. The ability to temporally shift power sales would also depend on the availability of energy storage [12], a factor hitherto identified both in the economic and technological dimensions. Various types of prosumer business models and associated benefits, such as selectivity, locality, value-tapping and participation willingness are of interest for further research.

Opportunities of new energy business models would also rely heavily on the degree of market deregulation and associated institutions [19, 29]. Financial incentives such as accelerated depreciation, feed-in-tariffs (FITs), and tradable certificates can accelerate renewable energy expansion, in addition to environmentalism and technological development [43]. Romero [37] suggested taxes and rebate mechanisms as opposed to subsidies as enablers of increased competition and business model sustainability. The strong interplay between the institutional dimension and new economic dynamics of P2P networks may be a juncture for integrated approaches in both academic and policy studies. 
While valuation trends and risk concerns would be important in discussions on cryptocurrency, the focus of this paper is on blockchain as an underlying P2P infrastructure. With this infrastructure, opportunities are created for several stakeholders in the energy sector. Blockchain can enable economic benefits on an individual level, in terms of economic entrepreneurship and independence [22], especially relevant for prosumers. However, distributed grids will also involve new market phenomena and behavior of which there is little current understanding [13]. Knowledge and skills related to blockchain and applications also require development $[20,66]$ in order to more effectively build and maintain prosumer business models. This indicates ties between the economic and social dimensions.

\subsection{Social dimension}

Blockchain may have significant impacts on societal values, social infrastructure, and corporate business models [26]. With these impacts, potential changes in behavior are important to comprehend when crafting new regulations and policies [16]. As put by Caputo et al. [1], sustainability depends on environmental protection, but also lies at the intersection of social and economic actors. When previous power consumers also become producers, or prosumers, they may feel more involved and thereby invested in the energy system $[1,13]$. How should users be engaged in effective cooperation to effectually benefit economic, social and environmental sustainability [1]?

\subsubsection{Socioeconomic incentives}

Several authors $[5,13,34]$ highlighted a need for further research on socioeconomic incentives needed for actors to participate in local energy markets, and how to incorporate these incentives into market design. Understanding prosumers' willingness to participate [59] and their diverse interests as well as concerns [58] would affect the success of P2P systems. In the local context, income equality is a key deliberation because unbalanced income distribution may hinder the acceptance and adoption of P2P trading among consumers and prosumers [59]. Local economy stimulation, arising from local resource use and profit creation [33, 24, 59], is also suggested as a key respect in grounding public acceptance.

Willingness to pay for renewable power may be higher in $\mathrm{P} 2 \mathrm{P}$ microgrids, for example, if citizens value the use of local renewables [34]. Green and Newman [13] discussed the potential of time-of-day FITs to incentivize batteries providing power during peak periods, enabling the reduction of peak generation capacities. Campbell [38] discussed the possibility of integrating blockchain and artificial intelligence to reward energy efficient behavior. Nicolson and Lotti [67] adopted game theory in simulations of potential prosumer behavior in $\mathrm{P} 2 \mathrm{P}$ power markets. The authors found that conventional cost-benefit frameworks used by policy-makers poorly represent real-life behavior, which may depend on several social factors including social relations and norms [67]. Such social and economic aspects are important when forming pricing and allocation mechanisms for a prosumer market [34].

P2P distributed power in microgrids can exploit aggregated local renewable sources and energy storage for increased energy autonomy and security in communities [11, 31, 32, 59]. Microgrid flexibility and islanding capabilities further contribute to energy security when facing utility grid outages [11]. Emissions and pollution reduction are also among the societal benefits and potential incentives of low- or zero-carbon microgrids [11,32, 34]. This indicates the abilities to integrate energy security and reduced pollution with mechanisms for enhanced self-sufficiency in P2P microgrids: an intersection between environmental and social sustainability of potential interest for policy-makers. National contexts would also affect the 
pertinence of such benefits. For example, in the United States emphasis is placed on energy security, while in the EU targets of emissions reduction lead to an emphasis on abilities to integrate renewables in microgrids [11].

Blockchain can enable consumer choice via polycentric governance in shared economies [22]. Users can be economically empowered with own identities in energy markets in P2P platforms [7]. Tanaka et al. [9] and Mengelkamp et al. [5] similarly highlighted the enhanced element of choice among energy consumers and prosumers arising with ICT and blockchain due to improved capacities in managing distributed data. For instance, abilities to select preferred energy sources $[5,34]$ and to trace each transaction back to its origin [16] would be possible. Choices can further incorporate characteristics such as timing, price ceilings/floors, quantity, and location [9, 13]. Such preferences can be included to a higher extent than in centralized, conventional energy systems [13]. In P2P energy markets, prosumers gain more control [22] with own conditions for trading, for instance, selecting to sell excess power directly or store it in batteries until wholesale prices are higher [13]. The enhanced element of choice may offer important socioeconomic benefits via P2P markets and windows for more sustainable behavior, but would require the development of new market regulations and incentives.

Effectual mechanisms for encouraging more sustainable behavior is a key research area for further investigation at large [1], not excluding the energy sector. In this context, it is useful to understand consumers, producers, prosumers, and their interactions. With the increased element of choice that blockchain can bring, it is suggested that such mechanisms are areas of interest for further investigation. Incentives via tokenization, i.e. the conversion of assets to tokens on blockchain platforms, present valuable opportunities for influencing more sustainable behavior [68]. For example, companies such as Energi Mine are exploring the use of digital tokens as rewards for energy efficiency and conservation [69].

The higher settlement frequency made possible by blockchain may be more effective than traditional pricing controls for encouraging sustainable choices [7]. User behavior influence on blockchain-based P2P microgrids (and vice versa) is yet to be empirically studied. By studying opinions and behavioral change through surveys, interviews and observation, empirically based contributions may be made towards understanding the social dimension of P2P energy system development. This would be important in investigating socioeconomic incentives for potential expansion of such systems and factors influencing social sustainability. This can in turn contribute to institutional development. Insight on multiple viewpoints and behavior in new energy systems is valuable for policy development [70], showing a strong link between grey areas in the institutional and social dimensions.

\subsubsection{Stakeholder interest management}

Several authors highlighted the importance of stakeholder interest management in the marketization and incentives of microgrids [32, 33, 58, 59]. Stakeholders include government, national grid corporations, microgrid owners, energy suppliers, equipment suppliers, and users [58]. In the case of P2P networks, prosumers are a new kind of user which will incur diverse bidding strategies [59]. Initially, it is imperative to explore perceptions and social acceptance of distributed grids [13].

Ozorhon et al. [43] discussed the importance of understanding consumer behavior and sharing information for increased acceptance of new energy systems. In a survey carried out by Accenture [71], the opinions of 
80,000 energy consumers related to new digital utility services were explored globally. Findings showed that technology-led approaches tend to be less adopted, while more successful strategies focused on personalized user experiences and the customer's level of digital engagement and skills [71]. Hence, it can be suggested that digital engagement is essential, in addition to the information-sharing discussed by Ozorhon et al. [43]. Bhuptani [72] and Thorén [73] similarly highlighted the need to improve the userfriendliness of interfaces for engagement in blockchain-based services at large.

While several nations have historically depended on fossil fuels and large power corporations [48], many policy-makers are shifting to distributed electricity, signifying an uncertain future for conventional utilities [12]. Such corporate concerns are also important to be explored further, for effective stakeholder interest management in system transitions. Digitalization is affecting utilities in terms of new business models, actors and roles on the grid [11, 13, 30,37]. Hirsch et al. [11] described a "utility death spiral" in which self-generation and -consumption in microgrids cause consumer demand reductions, increased power market prices, and thereby further reduction in demand. Hence current utilities are a key stakeholder and role to consider in any development of distributed, P2P microgrids. Due to the "utility death spiral", there may be a need to decouple revenues from power sales, for example via incentives for infrastructure management and efficiency efforts [11]. In this picture, utilities may become service or platform providers as opposed to energy suppliers in the future [37].

Soares et al. [35] highlighted that future grids and energy markets will require the coordination of several competing players, including producers, suppliers, consumers, prosumers, and energy service providers [35]. There may also be other new roles not pictured today. P2P power networks would incur new stakeholders, such as prosumers, as well as shifting roles of current electricity system stakeholders. Effective stakeholder interest management is vital in bridging between technological innovation, application, and commercialization by managing and leveraging such diverse stakeholder groups. This is an area of interest for further exploration in studies related to project and stakeholder management in $\mathrm{P} 2 \mathrm{P}$ microgrid development.

\subsubsection{Community engagement}

When consumers become prosumers that also produce electricity, levels of engagement in the system are likely to rise [1]. With the digitalization of energy, stakeholders may also be more attentive to energy [21]. User involvement and engagement are key opportunities with increasing digitalization [21], for example via interaction and visualization on digital platforms. Mengelkamp et al. [34] emphasized that public acceptance of P2P microgrids can be increased by co-development of objectives and market operations, and by effectively managing public relations. The authors also discussed that with effective energy management systems, the burden of $\mathrm{P} 2 \mathrm{P}$ trading can be lessened, profits enlarged, and thereby acceptance increased [34]. Hwang et al. [21] discussed that with both physical and virtual microgrids, actors may be more involved and thereby more interested in energy at large.

There are still several areas to be explored further in the social dimension via empirical research, such as surveys and interviews with users. What forms of value can essentially be added to user experiences via P2P energy networks? What user concerns are the most pertinent and how can they be overcome? Community-building of all affected stakeholders, expressly also including prosumers and consumers, is suggested as a potential mechanism for understanding and managing stakeholder interests in P2P microgrid 
planning and development. Multi-stakeholder discussions on blockchain and its applications may be valuable in skill-building as well as in gathering insight for informed institutional change [74]. Managerial studies of communication management and community-building in $\mathrm{P} 2 \mathrm{P}$ microgrid development are also an area for further investigation.

Communication strategies for user involvement are a key aspect to be facilitated in new digital energy services [71] and an area for further exploration. User perspectives and behavior in new energy systems comprise key insight needed in policy development [70]. For example, concerns on data privacy and security may grow with increased digitalization of the grid [12]. What are the success factors in P2P energy system user interfaces and experiences? Based on user involvement and various methods, such as surveyed feedback in real projects, such answers are essential in building the social pillars of institutional arches. It is also suggested that community-building and participatory planning can facilitate interest management $[32,33,35,58,59]$ and knowledge-sharing $[63,66,74]$ among the multiple stakeholders involved in P2P microgrids.

\subsection{Environmental dimension}

Emissions reduction is one of the potential benefits of microgrids [11, 57, 59, 60], and an important consideration in their development. This is especially pertinent considering that limiting global warming to even 1.5 degrees above pre-industrial levels would require "rapid, far-reaching and unprecedented changes in all aspects of society" [75]. Blockchain can contribute in this context, such as via enhanced traceability of greenhouse gas (GHG) emissions, transparency in emissions trading [76], and by inhibiting manipulation of data [36].

\subsubsection{Energy management and self-sufficiency}

Self-sufficiency can be a key indicator of ensuing environmental benefits of microgrids due to benefits of lower line losses and potentially higher renewable energy shares [11, 59]. In the long term, the interconnection of microgrids can enable distributed renewables, thereby contributing to emissions reduction [11, 32, 57]. Considering this benefit, regulations for emissions reduction could facilitate the development of P2P microgrids [57]. Basu et al. [57] and Di Silvestre et al. [30] highlighted the importance of incorporating environmental regulations into microgrid energy management, especially related to renewable energy and emissions reduction targets.

\subsubsection{Blockchain for environmentalism}

Khaqqi et al. [36] specifically highlighted the potential of blockchain and smart devices in emissions reduction strategies, such as for more effective emissions trading. This value is tied to blockchain transparency, which can shed light on tampering of emissions information [36]. Similarly, the United Nations Framework Convention on Climate Change (UNFCCC) has discussed blockchain as a major prospect in tackling climate change due to its "stakeholder involvement, transparency, and engagement" [76]. The organization outlines P2P blockchain-based energy trading, carbon emissions trading, GHG tracking and reporting, and crowd-funding of climate action support as key prospects [76]. The opportunities of blockchain for environmental sustainability are also increasingly recognized in the private sector. In terms of carbon emissions trading, for example, IBM and the Energy Blockchain Lab have partnered in developing a blockchain-based platform for carbon asset-trading in China [76, 77]. Hence, 
depending on jurisdiction and stakeholder interests, emissions reduction and GHG-tracking may be a key opportunity in blockchain-based P2P microgrids.

In addition, resource depletion and toxicity of microgrid equipment, such as end-of-life batteries, is a major environmental concern which is often overlooked [35]. In this context, blockchain may be able to contribute due to its ability of transparent, accountable tracking of material in supply chains [78, 79]. Zhang et al. [33] discussed the potential of blockchain for climate action and associated financial instruments, but emphasized the need of friendlier regulatory environments and legal reforms to enable blockchain utilization. Moving forward, prospects for integration of environmental laws and targets in smart contracts is of interest for further research both in academia and among policy-makers.

\subsection{Institutional dimension}

The blockchain is in its early days for business and rapidly developing, especially among startups, but without regulations and standards cleared out $[16,23,80]$. It has been visibly highlighted both in consulting reports $[15,23,25]$ and in academia [5, 6, 13, 17, 22] that policy is lagging behind technological development. Institutions are among the most challenging and influential dimensions of blockchain-based $\mathrm{P} 2 \mathrm{P}$ energy, as well as one of its largest research gaps [31]. There is an urgent need to bridge gaps of understanding on institutional implications. What will pricing mechanisms be [7]? What will the role of smart contracts be, and should they be mandatory [23]? What incentive structures will be in place [13, 15, $34]$ ?

Institutions can be formal, such as policies, standards and regulations [81], and informal, such as norms and customs [82]. Institutional foundations of blockchain for energy are still lacking in academia, but some authors have shared valuable discussions in bringing this forward. Potts et al. [22] explored the potential of blockchain to shift the smart city agenda to the "crypto city". The authors proposed that city services, not excluding energy, may be captured by new economic organizations such as civic associations [22]. Green and Newman [13] explored how the rapid expansion of solar PV and storage has contributed to "citizen utilities" in Australia. The authors discussed blockchain in this context, and the need for policy-makers to incorporate shifting roles of conventional utilities [13]. Mengelkamp et al. [34] developed seven components to analyze a blockchain-based microgrid in Brooklyn (New York City), including: setup, grid connection, information system, market, pricing, energy management, and regulation. All were found fulfilled to some extent except regulation: a key challenge inhibiting local energy markets in most countries [34].

\subsubsection{Market policy and grid codes}

The legal design of microgrids and fit into regulatory landscapes, with clear policies and standards, is a prerequisite for success $[31,34,57]$. Key aspects in this context are codes for grid access, interconnection, islanding and smart metering [11, 31, 34, 57]. By enabling interconnection [11] and with straightforward tariffs and market policies, microgrid participation and market competition can be increased [57]. The degree of energy market competition strongly influences microgrid realization [31, 32]. Policies in place for unbundled generation, transmission, distribution and retail are important elements in energy system transformations [31, 58]. Microgrid regulation changes are needed for further innovation, as these systems essentially transcend the limits of generation, transmissions and distribution [11]. There are some regions with institutions that facilitate microgrid development, such as the New York State Reforming the Energy 
Vision [11, 60]. The agenda puts resilient distributed energy at the core of its strategy [83], with market unbundling for enhanced competition [11].

Energy and smart technology innovation agendas, as well as their intersection, are central when discussing the institutional landscape of P2P networks. Entrepreneurial experimentation is a valuable driver of smart technology and energy innovation [29] in the public and private sectors. However, this may be inhibited by centralized forms of governance and the presence of utility monopolies. At large microgrids face regulatory challenges such as connection fees, drawn-out waiting times, or complete bans [60]. Limited grid connection ensuing from concerns on intermittency and grid capacity among incumbent utility monopolies $[11,29]$ negatively affects microgrid and prosumer business models. Soares et al. [35] stressed the importance of policies and market design to incorporate business model innovation (and vice versa). Utility grid control and exclusive franchises constrain market competition [11], affecting the potential of P2P microgrid participation.

\subsubsection{P2P microgrid policies and governance}

Specific regulations are necessary for blockchain-based power exchange and sustainable business models in the long term [34, 59]. There is a need of new laws for the buying and selling of P2P power [37, 63]. For example, the mentioned case in Brooklyn [34] is based on renewable energy certificate sales for prosumer solar power, as this electricity cannot yet be legally traded [37, 84]. Key legal issues related to microgrids also involve unclear identities and obligations on power markets [11]. Clear legal identity development of microgrids and prosumers, and frameworks for the selling and purchasing of electricity, is in need of further exploration [11]. For instance, to participate in power markets, a prosumer would require a license which may call for continuous supplies meeting counterparty loads, and even customer support [63]. This system appears impractical for smaller-scale prosumers, as licenses usually assume larger scale producers and companies [63]. In this context, clear ownership and partnership models, both for energy and microgrid infrastructure would also be key considerations [31, 32, 48, 62]. Ultimately, it can be suggested that if P2P energy markets are to feasibly develop in the long-term, ownership and partnership models, prosumer licensing and associated requirements and market roles would require further research.

A microgrid can appear as a consumer or producer to the utility grid, lessening the challenges of distributed resource integration by aggregating individual microgrid consumers and prosumers [11, 21, 34]. Some researchers also proposed multi-microgrid networks, whereby each microgrid acts as an aggregated virtual power plant (VPP), conducts bidding in the larger network, and provides ancillary services [11]. It is of interest to also explore various forms of blockchain governance for various microgrid systems and potential stages of development. Transparency [17] and new forms of decentralized value creation may be pivotal factors for blockchain. However, blockchain platform governance is a key issue. For example, will the platform be private, semi-private, consortium, or public? How will smart contracts and disputes be managed?

A private blockchain runs on digital identities within an organization for auditing, governance, dispute management [16], and internal transactions [34]. For scaling, this may be changed to a semi-private blockchain in which access is permissioned to any qualifying user by a central entity [56]. In consortium blockchains, consensus mechanisms are carried out by a selected group of nodes while the information can be shared publicly, useful for banking as well as the energy sector [85]. This can potentially be followed 
by larger scale public blockchains which would require the highest degree of regulatory change [16]. Potts et al. [22] discussed that governments may go from data facilitators to platform providers. In this setting, public agencies may be a key player in energy blockchain governance [48]. For stepwise institutional development parallel to energy and blockchain progress, it can be suggested that platform governance is also gradually developed.

\subsubsection{Prospects for institutional innovation}

Several authors highlighted the need to explore grey areas in institutions related to blockchain and its applications [14, 23, 34]. This is not a straightforward question. As discussed, technology innovation, environmental agendas, social dynamics, and economic markets are all influential in P2P microgrids. It is suggested that these dimensions are therefore also vital in discussions on institutional change. Considering the multi-faceted nature of blockchain applications, all public sectors would need to be involved in order to overcome siloes, explore applications with societal impact [74], and achieve regulatory consistency among ministries [66]. As highlighted in the social dimension, community-building can be an effective mechanism for knowledge-sharing, to empower both the private and public sectors, and inform new policies [63, 66, 74]. Yarime and Karlsson [29] similarly highlighted a need of stakeholder involvement, knowledge-sharing, and skill-building for energy sector innovation.

Digital technologies appear to be more impactful in markets with less constraining regulatory frameworks, thereby facilitating a shift in roles and development [30]. Entrepreneurial experimentation is a vital element for energy and smart technology innovation [29]. Governments tend to be risk-averse when engaging in the rapid development of blockchain and associated security liabilities [16, 37, 48]. However, through strategic deployment via pilot projects with relevant partners, governments may both effectively cope with and influence the course of such rapid change [23]. Hsu [80] similarly highlighted the importance of regulators to work with industry in building mutual awareness and forming new policies for blockchain innovation. Regulatory sandboxes are spaces where industry can collaborate with the public sector and involve citizens in testing innovative products and services in real settings [86]. For example, service trials can be run preceding full launch of new energy services [87]. A regulatory sandbox approach may inform the development of substantiated institutions via an experimental, multi-stakeholder approach rooted in reallife contexts.

Strategic, stepwise development based on community-building with relevant stakeholders can aid in directing change [23], and simultaneously empower citizens via participatory planning and involvement $[22,35]$. In this way, the interests and concerns of stakeholders may be more easily understood and incorporated into effectual institutions. The perceptions of various social groups influence low-carbon system development [70]. New policies benefit from flexibility as well as an understanding of the multiple viewpoints and behaviors of actors and networks [70]. This form of progressive change may be based on multi-stakeholder regulatory sandbox approaches [80], for progress in institutional readiness leveraging insight on all dimensions in TESEI. Exactly how such approaches would be structured and executed, as well as evaluation of ensuing outcomes, is of interest to explore further. For example, prosumer licensing, blockchain governance, and microgrid ownership and partnership models are all factors identified in this paper for further exploration which may be studied via regulatory sandboxes.

\subsection{Main takeaways: Pillars of institutional development}


A compilation of key factors identified in each dimension of TESEI, including sub-factors useful in discussing them, is shown in Table 1. Hanna et al. [60] emphasized the interaction of technology, policy and markets in evaluation of microgrid business models. This is also clear in the interplay of policy deliberations with digital currency and blockchain technology development seen worldwide [17]. Similarly, all TESEI dimensions are inter-related. An illustrative example of a blockchain-based P2P microgrid in the context of TESEI is shown in Figure 4. This shows a simplified network with two prosumers and one consumer on a microgrid connected to a utility grid, and coordinated via digital inverters in a broader P2P network based on [9]. Each dimension of TESEI is indicated, and the inter-relatedness of the dimensions illustrated with a circularity.

This circularity suggests that progressing from technological to institutional readiness also requires the incorporation of environmental, social, and economic dimensions. For example, P2P microgrids require clearer policies and standards in both regulatory [31, 34, 57] and economic [57] dimensions. Energy systems of today are gradually being digitalized, and energy markets liberalized. The coupling of these two transformations facilitates microgrid development $[31,57,58]$. Incorporating trading mechanisms for zero-

Table 1. TESEI framework for blockchain-based P2P microgrid analysis.

\begin{tabular}{|c|c|c|c|c|}
\hline Technological & Economic & Social & Environmental & Institutional \\
\hline $\begin{array}{l}\text { - Energy management } \\
\text { system: automatic } \\
\text { management of energy } \\
\& \text { bidding strategies [9, } \\
11,24,34,59], \\
\text { frequency and voltage } \\
\text { control [9, 11], } \\
\text { reliability [11, 12, 24, } \\
\text { 32, 57] } \\
\text { - Power grid: smart } \\
\text { metering [9, 31, 57], } \\
\text { energy storage [11, 12], } \\
\text { O\&M of microgrid [60, } \\
62], \text { virtual \& physical } \\
\text { grid connection [30, } \\
34], \text { P2P microgrid- } \\
\text { utility grid } \\
\text { interoperability [63] \& } \\
\text { islanding [11, 12, 31, } \\
34,57], \text { microgrid } \\
\text { power loss [64] } \\
\text { - P2P network } \\
\text { system: smart } \\
\text { contracts \& consensus } \\
\text { mechanisms [9, 20, 24, } \\
\text { 34], cybersecurity [48, } \\
\text { 20], data storage [20, } \\
\text { 24] }\end{array}$ & $\begin{array}{l}\text { - Energy market } \\
\text { mechanisms: } \\
\text { competition [31, 57, } \\
\text { 58], scheduling [24, } \\
60], \text { real-time pricing } \\
\text { [24, 34, 35, 57] for } \\
\text { frequent power fee } \\
\text { settlements [24], } \\
\text { ancillary service } \\
\text { participation [32, 57] } \\
\text { - Prosumer } \\
\text { business models: } \\
\text { selectivity \& locality } \\
\text { [32], value-tapping } \\
\text { \& participation } \\
\text { willingness [59] } \\
\text { - Smart contracts: } \\
\text { business model } \\
\text { support [19, 59] } \\
\text { through automated } \\
\text { purchase \& selling } \\
\text { strategies [19, 24], } \\
\text { smart-utility contract } \\
\text { interoperability [63] }\end{array}$ & $\begin{array}{l}\text { - Socioeconomic } \\
\text { incentives: local } \\
\text { economy growth [33, } \\
\text { 34, 50], income equality } \\
\text { [59], reduced pollution } \\
\text { [11, 32, 34, 60], energy } \\
\text { security [11, 24, 32, 57], } \\
\text { enhanced } \\
\text { consumer/prosumer } \\
\text { choice [7, 9, 34], } \\
\text { sustainable behavior [1, } \\
\text { 7] } \\
\text { - Stakeholder interest } \\
\text { management [12, 13, } \\
\text { 32, 33, 35, 58, 59]: } \\
\text { interests, concerns \& } \\
\text { acceptance [12, 13, 58], } \\
\text { shifting roles [11, 30, } \\
\text { 37], user friendliness } \\
\text { [71-73] } \\
\text { - Community } \\
\text { engagement: } \\
\text { communication [71], } \\
\text { public acceptance [13, } \\
\text { 34, 58], stakeholder skill } \\
\text { development [20, 71, } \\
\text { 74] }\end{array}$ & $\begin{array}{l}\text { - Emissions } \\
\text { reduction: energy } \\
\text { management for } \\
\text { emissions reduction } \\
{[11,57,59,60] \text {, }} \\
\text { emission regulations } \\
\text { in smart contracts } \\
\text { [57] } \\
\text { - Self-sufficiency: } \\
\text { higher renewable } \\
\text { share, lower line } \\
\text { losses [11, 57, 59] } \\
\text { - Life-cycle impact: } \\
\text { tracking microgrid } \\
\text { equipment end-of- } \\
\text { life impact and } \\
\text { recycling [35] }\end{array}$ & $\begin{array}{l}\text { - Market policy: } \\
\text { liberalization [31, 32], } \\
\text { microgrid ancillary } \\
\text { service market [11, 32, } \\
\text { 57], emission } \\
\text { regulations [57] } \\
\text { - Grid codes: for } \\
\text { microgrid } \\
\text { interconnection, } \\
\text { islanding, metering [11, } \\
\text { 31, 34, 57] } \\
\text { - P2P policy: prosumer } \\
\text { licenses [11, 63], } \\
\text { ownership \& sharing } \\
\text { models for } \\
\text { infrastructure \& energy } \\
\text { [31, 32, 62], blockchain } \\
\text { governance [48] } \\
\text { - Institutional } \\
\text { innovation } \\
\text { mechanisms: } \\
\text { community-building \& } \\
\text { reduced silos [63, 66, } \\
\text { 74], co-development } \\
\text { [58, 74], regulatory } \\
\text { sandbox [80, 86, 87] }\end{array}$ \\
\hline
\end{tabular}


INSTITUTIONS - Market policy, grid codes, P2P

policy, mechanisms for institutional innovation

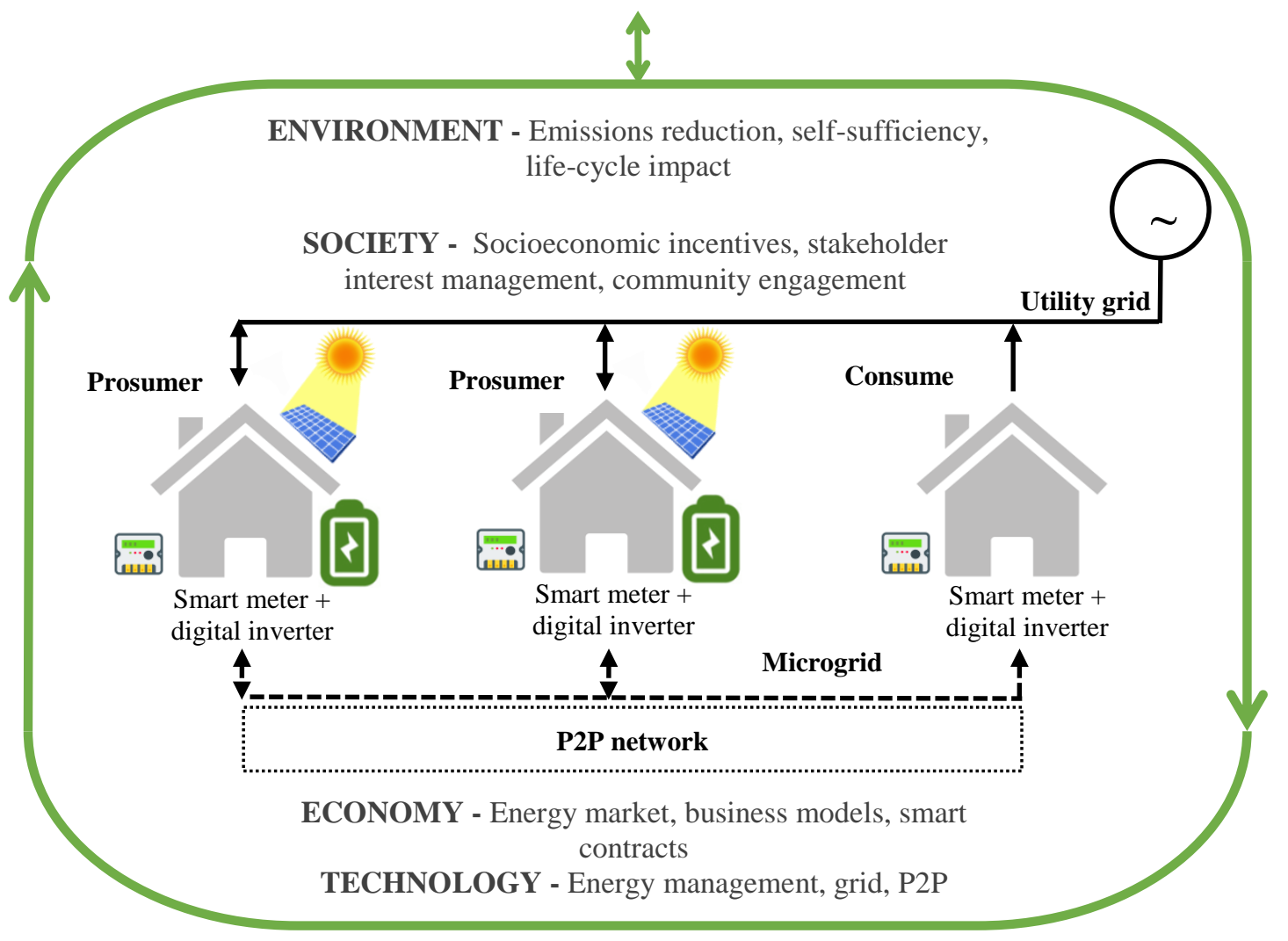

Fig 4. TESEI framework in the context of an illustrative, simplified example of a blockchain $\mathrm{P} 2 \mathrm{P}$ power microgrid. Adapted from Tanaka et al. [9]

or low-carbon resources, environmental regulations [57], as well as clear P2P trading mechanisms [57, 59] may contribute to institutional readiness in the intersection of environmental and economic sustainability. The influence of market liberalization and innovation on microgrid success suggests a need for economic decentralization in addition to the technological distribution made possible by blockchain. It can be argued the increasing technological decentralization of energy systems would also call for decentralization in social, economic market, environmental, and institutional systems. For example, in the social dimension a need of research on socioeconomic incentives, acceptance and local co-development of P2P microgrids was identified. Blockchain mechanisms technically enable sharing and transparency in multi-partner, effective P2P networks. It is suggested that this decentralization would likewise need to be reflected in social systems and stakeholder management: a strong tie between the technological and social dimensions.

Both from technological and market perspectives, the interoperability and progressive integration of conventional and new P2P systems also constitute vital points for further research. P2P energy-sharing solutions are increasing [59], with potential to rapidly progress and overcome barriers such as scalability and data storage. How can this progress be facilitated via a gradual transformation from current to new institutions? As put by Soares et al. [35], "sustainability is by definition a long term goal." Strategic, stepwise institutional change rooted in current contexts is suggested, drawing from existing hard and soft 
infrastructure such as utility grids, market structures, and human skillsets. In a process of "creative syncretism", systems and actor behavior may undergo gradual change in relation to previous institutions, regardable as a mutable basis for new institutions [88]. It is suggested that this gradual, syncretic approach would be appropriate to facilitate interoperability between conventional and forthcoming energy systems. This may be explored via regulatory sandboxes, incorporating community-building, and stakeholder involvement in building parallel pillars and milestones for institutional development. This may contribute by reducing silos between industry and government, and among sectors, in laying institutional groundwork.

\section{Conclusions}

The purpose of this paper was to holistically explore and conceptualize blockchain-based P2P microgrids, and propose practical implications for institutional development as well as academic research. Based on a comprehensive review, an analytical framework for blockchain-based P2P microgrids was created. Titled TESEI, the framework includes 1) Technological, 2) Economic, 3) Social, 4) Environmental, and 5) Institutional dimensions. Core factors narrowed down in each dimension are:

1. Technology: energy management system, power grid, P2P network.

2. Economy: energy market mechanisms, prosumer business models, smart contracts.

3. Social: socioeconomic incentives, stakeholder interest management, community engagement.

4. Environment: emissions reduction, self-sufficiency, life-cycle impact.

5. Institutions: market policy, grid codes, P2P policy, mechanisms for institutional innovation.

It is important to note that each dimension would be contingent on local conditions and stakeholders, and the identified factors may not be universally applicable. Generalizable findings for each dimension are open to further research. However, it is suggested that the created framework can offer useful insight on the concept and multi-dimensionality of blockchain-based P2P microgrids, which would be important in academia, case analyses, and in framing directions for institutional development. At large it is suggested that there is a need to bridge the gap between technology and institutions by also incorporating economic, social, and environmental dimensions. The reasoning here is that an omitted dimension would denote a missing pillar needed in institutional change. Community-building and regulatory sandboxes may enable substantiated institutional development in conjunction with all dimensions, by leveraging multiple perspectives, knowledge-sharing, and reduced cross-sectoral siloes. A gradual, multi-dimensional approach may contribute to interoperability between current and future systems through stepwise syncretic progress. Thereby, holistic institutional readiness may be possible for blockchain-based energy systems: a noteworthy implication for energy and sustainable development at large.

\section{Acknowledgements}

This research did not receive any specific grant from funding agencies in the public, commercial, or notfor-profit sectors.

\section{References}

[1] Caputo F, Buhnova B, Walletzky L. Investigating the role of smartness for sustainability: insights from the Smart Grid domain. Sustainability Science 2018; 13: 1299-1309.

[2] IEA. Global energy demand grew by $2.1 \%$ in 2017 , and carbon emissions rose for the first time since 2014. International Energy Agency (IEA), https://www.iea.org/newsroom/news/2018/march/global- 
energy-demand-grew-by-21-in-2017-and-carbon-emissions-rose-for-the-firs.html; 2018 [accessed August 13 2018].

[3] Vaughan A. EU raises renewable energy targets to $32 \%$ by 2030 . The Guardian, https://www.theguardian.com/business/2018/jun/14/eu-raises-renewable-energy-targets-to-32-by-2030; 2018 [accessed August 15 2018].

[4] Gray A. Sweden to reach its 2030 renewable energy target this year. World Economic Forum, https://www.weforum.org/agenda/2018/07/sweden-to-reach-its-2030-renewable-energy-target-this-year/; 2018 [accessed July 15 2018].

[5] Mengelkamp E, Notheisen B, Beer C. Blockchain-based smart grid: towards sustainable local energy markets. Computer Science - Research and Development, 2018; 33(1-2): 207-214.

[6] Calvillo CF, Sanchez-Miralles A, Villar J. Energy management and planning in smart cities. Renewable and Sustainable Energy Reviews 2016; 55: 273-287.

[7] Memoori. Blockchain and the Energy System of the Future. Smart Building Research, Memoori, https://www.memoori.com/blockchain-energy-system-future/; 2017 [accessed August 13 2018].

[8] Pop C, Cioara T, Antal M, Anghel I, Salomie I, Bertoncini M. Blockchain Based Decentralized Management of Demand Response Programs in Smart Energy Grids. Sensors 2018; 18(1): 162.

[9] Tanaka K, Nagakubo K, Abe R. Blockchain-based electricity trading with Digitalgrid router. IEEE International Conference on Consumer Electronics, Taiwan, 2017.

[10] Efanov D, Roschin P. The All-Pervasiveness of the Blockchain Technology. Procedia Computer Science 2018; 123: 116-121.

[11] Hirsch A, Parag Y, Guerrero J. Microgrids: A review of technologies, key drivers, and outstanding issues. Renewable and Sustainable Energy Reviews 2018; 90: 402-411.

[12] Cruz MRM, Fitiwi DZ, Santos SF, Catalão JPS. A comprehensive survey of flexibility options for supporting the low-carbon energy future. Renewable and Sustainable Energy Reviews 2018; 97: 338-353.

[13] Green J, Newman P. Citizen utilities: The emerging power paradigm. Energy Policy 2017; 105: 283293.

[14] Tapscott D, Tapscott A. Blockchain Revolution: How the Technology Behind Bitcoin Is Changing Money, Business, and the World. London: Portfolio; 2016.

[15] Killmeyer J, White M, Chew B. Will blockchain transform the public sector?: Blockchain basics for government. Deloitte Center for Government Insights, Deloitte Press, https://www2.deloitte.com/content/dam/insights/us/articles/4185_blockchain-public-sector/DUP_willblockchain-transform-public-sector.pdf; 2017 [accessed August 14 2018]

[16] Wong M. Personal communication. Associate Professor of Finance, Department of Economics and Finance, City University of Hong Kong. Interviewed by: Ahl A. 12 September, 2018. 
[17] Gabison GA. Policy Considerations for the Blockchain Technology Public and Private Applications. European Commission; 2016.

[18] Buterin V. Unpublished results. Co-founder, Ethereum. Updates and Future Plan of Ethereum. Ethereum Industry Summit (ETHIS), Hong Kong, 2018.

[19] Park C, Yong T. Comparative review and discussion on P2P electricity trading. Energy Procedia 2017; 128: 3-9.

[20] Wu J, Tran N. Application of Blockchain Technology in Sustainable Energy Systems: An Overview. Sustainability 2018; 10(9): 3067.

[21] Hwang J, Choi M, Lee T, Jeon S, Kim S, Park S, Park S. Energy Prosumer Business Model Using Blockchain System to Ensure Transparency and Safety. Energy Procedia 2017; 141: 194-198.

[22] Potts J, Rennie E, Goldenfein J. Blockchains and the crypto city. IT - Information Technology 2017; 59(6): 285-293.

[23] Cheng S, Daub M, Domeyer A, Lundqvist M. Using blockchain to improve data management in the public sector. Digital McKinsey, McKinsey \& Company, https://www.mckinsey.com/businessfunctions/digital-mckinsey/our-insights/using-blockchain-to-improve-data-management-in-the-publicsector; 2017 [accessed August 13 2018]

[24] Noor S, Yang W, Guo M, van Dam KH, Wang X. Energy Demand Side Management within microgrid networks enhanced by blockchain. Applied Energy 2018; 228: 1385-1398.

[25] Raconteur. The future of blockchain in 8 charts, https://www.raconteur.net/business-innovation/thefuture-of-blockchain-in-8-charts; 2016 [accessed August 13 2018].

[26] WU GTPC. Blockchain 101 for Governments. Vienna University (WU) of Business and Economics, Global Tax Policy Center (GTPC), http://www.un.org/esa/ffd/wpcontent/uploads/2017/10/15STM Blockchain-101.pdf; 2017 [accessed July 29 2018].

[27] Livemint. World Bank to issue world's first blockchain bond, https://www.livemint.com/Money/b6mdrwIPPKcSU5XtxNZtKO/World-Bank-to-issue-worlds-firstblockchain-bond.html; 2018 [accessed August 16 2018].

[28] Carlström V. Central bank of Denmark is considering an e-krone based on blockchain - but tech is the least of the problems involved. Business Insider Nordic, https://nordic.businessinsider.com/thedanish-central-bank-is-considering-an-ekrona-based-on-blockchain---but-privacy-could-be-a-problem2016-12/; 2016 [accessed September 18 2018].

[29] Yarime M, Karlsson M. Examining the Technological Innovation Systems of Smart Cities: The Case of Japan and Implications for Public Policy and Institutional Design. In: Niosi J editor. Innovation Systems, Policy and Management, United Kingdom: Cambridge University Press; 2018, p. 394-417.

[30] Di Silvestre ML, Favuzza S, Riva Sanseverino E, Zizzo G. How Decarbonization, Digitalization and Decentralization are changing key power infrastructures. Renewable and Sustainable Energy Reviews 2018; 93: 483-498. 
[31] Wouters C. Towards a regulatory framework for microgrids - The Singapore experience. Sustainable Cities and Society 2015; 15: 23-32.

[32] Morris GY, Abbey C, Wong S, Joos G. Evaluation of the Costs and Benefits of Microgrids with Consideration of Services beyond Energy Supply. IEEE Power and Energy Society General Meeting, San Diego, USA, 2012.

[33] Zhang C, Wu J, Long C, Cheng M. Review of Existing Peer-to-Peer Energy Trading Projects. Energy Procedia 2017; 105: 2563-2568.

[34] Mengelkamp E, Gärttner J, Rock K, Kessler S, Orsini L, Weinhardt C. Designing microgrid energy markets: A case study: The Brooklyn Microgrid. Applied Energy 2018; 210: 870-880.

[35] Soares N, Martins AG, Carvalho AL, Caldeira C, Du C, Castanheira É, et al. The challenging paradigm of interrelated energy systems towards a more sustainable future. Renewable and Sustainable Energy Reviews 2018; 95: 171-193.

[36] Khaqqi KN, Sikorski JJ, Hadinoto K, Kraft M. Incorporating seller/buyer reputation-based system in blockchain-enabled emission trading application. Applied Energy 2018; 209: 8-19.

[37] Romero T. Personal communication. Chief Technology Officer (CTO), Business Innovation Task Force, Tokyo Electric Power Company (TEPCO). Interviewed by: Ahl A. May 25 2018. (Note: not official statement of TEPCO).

[38] Campbell R. Energi Mine Launches Blockchain Based Platform to Reward Energy Conservation. CoinJournal, https://coinjournal.net/energi-mine-launches-blockchain-based-platform-reward-energyconservation/; 2017 [accessed August 13 2018].

[39] Streb CK. Exploratory Case Study. In: Mills AJ, Durepos G, Wiebe E, editors. Encyclopedia of Case Study Research, Thousand Oakes CA: Sage Publications; 2010, p. 372-373.

[40] Van Wyk B. Research design and methods Part 1. University of the Western Cape, https://www.uwc.ac.za/Students/Postgraduate/Documents/Research_and_Design_I.pdf; 2012 [accessed October 18 2018]

[41] Turner DW. Qualitative Interview Design: A Practical Guide for Novice Investigators. The Qualitative Report 2010; 15(3): 754-760.

[42] Pohekar SD, Ramachandran M. Application of multi-criteria decision making to sustainable energy planning - A review. Renewable and Sustainable Energy Reviews 2004; 8(4): 365-381.

[43] Ozorhon B, Batmaz A, Caglayan S. Generating a framework to facilitate decision making in renewable energy investments. Renewable and Sustainable Energy Reviews 2018; 95: 217-226.

[44] Afgan NH, Carvalho MG. Multi-criteria assessment of new and renewable energy power plants. Energy 2002; 27(8): 739-755.

[45] Katre A, Tozzi A. Assessing the Sustainability of Decentralized Renewable Energy Systems: A Comprehensive Framework with Analytical Methods. Sustainability 2018; 10(4): 1058. 
[46] Oh S, Kim M, Park Y, Roh G, Lee C. Implementation of blockchain-based energy trading system. Asia Pacific Journal of Innovation and Entrepreneurship 2018; 11(3): 322-334.

[47] Bloomberg J. Don't Let Blockchain Cost Savings Hype Fool You. Forbes, https://www.forbes.com/sites/jasonbloomberg/2018/02/24/dont-let-blockchain-cost-savings-hype-foolyou/\#7ee163015811; 2018 [accessed September 7 2018].

[48] Mishra S. Personal communication. Lead Research Engineer, Siemens Technology India (October 2016 - January 2018). Interviewed by: Ahl A. October 192018.

[49] EdChain. Blockchain FAQ \#3: What is Sharding in the Blockchain?. Medium, https://medium.com/edchain/what-is-sharding-in-blockchain-8afd9ed4cff0; 2018 [accessed October 15 2018].

[50] Prentiss T. Any Truth to EOS Investor Claim That The Blockchain Now Handles 5,000 Transactions Per Second? ETH News, https://www.ethnews.com/any-truth-to-eos-investor-claim-that-the-blockchainnow-handles-5-000-transactions-per-second; 2018 [accessed October 15 2018].

[51] Samani K. The Bull and Bear Cases for EOS. Forbes, https://www.forbes.com/sites/ksamani/2018/04/25/the-bull-and-bear-cases-for-eos/\#db7593242c05; 2018 [accessed October 16 2018].

[52] Nafqvi SF. Lets shard the blockchain using sidechains. Medium, https://medium.com/karachain/letsshard-the-blockchain-using-sidechains-ea42d98b7b28; 2018 [accessed October 16 2018].

[53] Lee S. Explaining Side Chains, The Next Breakthrough In Blockchain. Forbes, https://www.forbes.com/sites/shermanlee/2018/02/07/explaining-side-chains-the-next-breakthrough-inblockchain/\#516a16a052eb; 2018 [accessed October 16 2018].

[54] Bergman A. Taxation of Cryptocurrency Proof Of Stake Transaction Fees. Forbes, https://www.forbes.com/sites/greatspeculations/2018/03/02/taxation-of-cryptocurrency-proof-of-staketransaction-fees/\#39dea88c416c; 2018 [accessed October 23 2018].

[55] Bambrough B. Ethereum's Mining Infrastructure Is About To Get A Big Boost. Forbes, https://www.forbes.com/sites/billybambrough/2018/08/30/ethereums-mining-infrastructure-is-getting-abig-boost/\#e4390c96f871; 2018 [accessed September 2 2018].

[56] Mougayar W. Understanding Semi-private Blockchain Applications. Startup Management, http://startupmanagement.org/2016/11/06/understanding-semi-private-blockchain-applications/; 2016 [accessed September 25 2018].

[57] Basu AK, Chowdhury SP, Chowdhury S, Paul S. Microgrids: Energy management by strategic deployment of DERs - A comprehensive survey. Renewable and Sustainable Energy Reviews 2011; 15: 4348-4356.

[58] Long Y, Wang Y, Pan C. Incentive Mechanism of Microgrid Project Development. Sustainability 2018; 10(1): 163 . 
[59] Zhou Y, Wu J, Long C. Evaluation of peer-to-peer energy sharing mechanisms based on a multiagent simulation framework. Applied Energy 2018; 222: 923-1022.

[60] Hanna R, Ghonima M, Kleissl J, Tynan G, Victor DG. Evaluating business models for microgrids: Interactions of technology and policy. Energy Policy 2017; 103: 47-61.

[61] Tsukamoto O, Morozumi S. Grid code development in Japan. International Conference on Integration of Renewable and Distributed Resources, Kyoto, Japan, http://www.nedo.go.jp/english/ired2014/program/pdf/s2/s2_2_osami_tsukamoto.pdf; 2014.

[62] Juan L, Shiju W, Jing X, Xuefei Z, Peng L. Research on Microgrid Distribution Network and Its Operation Efficiency in the Energy Internet. 2nd International Conference on Power and Renewable Energy, Taiwan, 2017.

[63] Ogushi, Y. Personal communication. Energy blockchain specialist. Interviewed by: Ahl A. 17 September, 2018

[64] Di Silvestre ML, Gallo P, Ippolito MG, Sanseverino ER, Zizzo G. A Technical Approach to the Energy Blockchain in Microgrids. IEEE Transactions on Industrial Informatics 2018; 14(11): 4792-4803.

[65] Jackson F. Blockchain: Downfall Or The Future Of Utilities? Forbes, https://www.forbes.com/sites/feliciajackson/2018/04/10/blockchain-nemesis-or-future-forutilities/\#3e6156114f0b; 2018 [accessed October 19 2018].

[66] Suzuki S. Personal communication. Associate Director, Blockchain Laboratory, Keio Research Institute, Japan. Interviewed by: Ahl A. September 142018.

[67] Nicolson ML, Lotti L. Democratising the energy market: applying behavioural game theory to peerto-peer electricity trading markets. Political Studies Association Annual International Conference, Cardiff, United Kingdom, 2018.

[68] Chu J. Unpublished. Managing Partner, Kenetic Capital. Non-Fungible Tokens (NFTs) and Gaming. In: Ethereum Industry Summit (ETHIS), Hong Kong, 2018.

[69] Harrison K. Blockchain May Be The Key To A Sustainable Energy Future. Forbes, https://www.forbes.com/sites/kateharrison/2018/02/14/blockchain-may-be-the-key-to-a-sustainableenergy-future/\#206f9e0c644c; 2018 [accessed October 23 2018].

[70] Axsen J, Kurani KS. Social Influence, Consumer Behavior, and Low-Carbon Energy Transitions. Annual Review of Environment and Resources 2012; 37: 311-340.

[71] Accenture. New Energy Consumers A new way for agile management, https://www.accenture.com/t20171222T014126Z_w_/jp-ja/_acnmedia/PDF-68/Accenture-NEC2017Main-Insights-POV-Japan.pdf\#zoom=50; 2017 [accessed 12 September 2018] Japanese.

[72] Bhuptani, A. Unpublished results. Co-founder, Connext Inc. Connext: Production Ready Payment Channel Hubs on Ethereum. In: Ethereum Industry Summit (ETHIS), Hong Kong, 2018.

[73] Thorén O. Unpublished results. Head of Engineering, Status. Ethereum, everywhere and everyone. In: Ethereum Industry Summit (ETHIS), Hong Kong, 2018. 
[74] Kurihara K. Unpublished results. President Tokyo Chapter at Government Blockchain Association. Panel discussion: Communities around blockchain. Associations, hubs, labs. In: Unblock Community Conference, Hong Kong, 2018.

[75] IPCC. Summary for Policymakers of IPCC Special Report on Global Warming of 1. $5^{\circ} \mathrm{C}$ approved by governments. Intergovernmental Panel on Climate Change (IPCC), Press Release, 8 October 2018.

[76] UNFCCC. How Blockchain Technology Could Boost Climate Action. United Nations Framework Convention on Climate Change (UNFCCC), https://unfccc.int/news/how-blockchain-technology-couldboost-climate-action; 2017 [accessed 19 October 2018].

[77] IBM. Energy Blockchain Labs, https://www.ibm.com/case-studies/energy-blockchain-labs-inc; 2018 [accessed 19 October 2018].

[78] Marr B. How Blockchain Will Transform the Supply Chain and Logistics Industry. Forbes, https://www.forbes.com/sites/bernardmarr/2018/03/23/how-blockchain-will-transform-the-supply-chainand-logistics-industry/\#5dbaf79d5fec; 2018 [accessed 19 October 2018].

[79] Korpela K, Hallikas J, Dahlberg T. Digital Supply Chain Transformation toward Blockchain Integration. Hawaii International Conference on System Sciences (HICSS), 2017.

[80] Hsu J. Unpublished results. Congressman, Legislative Yuan of Taiwan. Panel discussion: How Will Investors Respond to "Bull Market" and "Bear Market"? In: Ethereum Industrial Summit (ETHIS), Hong Kong, 2018.

[81] Nam T, Pardo TA. Conceptualizing Smart City with Dimensions of Technology, People and Institutions. The Proceedings of the 12th Annual International Conference on Digital Government Research, 2011.

[82] Berman S. Ideational theorizing in the social sciences since 'Policy paradigms, social learning and the state'. Governance 2013; 26(2): 217-237.

[83] NYS. Reforming the Energy Vision. New York State (NYS), https://rev.ny.gov/; 2018 [accessed September 13, 2018].

[84] Cardwell D. Solar Experiment Lets Neighbors Trade Energy Among Themselves. The New York Times, https://www.nytimes.com/2017/03/13/business/energy-environment/brooklyn-solar-grid-energytrading.html; 2017 [accessed September 20 2018].

[85] ILTA. The 4 Types of Blockchain Networks Explained. International Legal Technology Association (ILTA), https://www.iltanet.org/blogs/deborah-dobson/2018/02/13/the-4-types-of-blockchain-networksexplained?ssopc $=1 ; 2018$ [accessed October 22 2018].

[86] EY. The emergence and impact of regulatory sandboxes - in the UK and across Asia-Pacific. Ernst and Young (EY); 2017. 
[87] Nicolson ML, Fell MJ, Huebner G. Consumer demand for time of use electricity tariffs: A systematized review of the empirical evidence. Renewable and Sustainable Energy Reviews 2018; 97: 276-289.

[88] Berk G, Galvan D. How people experience and change institutions: a field guide to creative syncretism. Theory and Society 2009; 38: 543-580. 